\title{
Education in Ultrasonography - when to start and when to stop
}

\section{Roxana Șirli, Ioan Sporea}

\begin{abstract}
Department of Gastroenterology and Hepatology, "Victor Babeș” University of Medicine and Pharmacy, Timișoara,
\end{abstract} Romania

Since introduced in clinical practice more than 60 years ago, ultrasound has become a useful tool in almost every medical specialty. Nowadays, specialties such as Gastroenterology, Cardiology, Obstetrics (and others, we are sure) are unthinkable without ultrasonography (US). In the last 10-20 years, special branches of US (contrastenhanced ultrasonography, elastography - to name only two) have been developed and entered in daily practice. The amount of valuable clinical information that this method achieves has made it almost indispensable. Furthermore, ultrasound machines are now ultraportable, and can be used almost anywhere. As a consequence of all of the above, point-of-care ultrasound (US imaging performed and interpreted at a patient's bedside by a clinician) is becoming more and more an everyday practice.

However, US is an operator-dependent method and, in order to be able to use it at its full potential, quality training is required. National and international professional societies have issued recommendations for minimal training in different branches of US but we shall not discuss them here. What we want to discuss is if it would be useful to start education in US in students and when, if ever, should education in US stop.

Considering the expansion of point-of-care ultrasound in the last 10 years, it seems logical to start undergraduate ultrasound education, to train emerging physicians. Worldwide, ultrasound training for medical students has been implemented for several years, but there is no con-

Received Accepted

Med Ultrason

2020, Vol. 22, No 3, 263-264

Corresponding author: Prof Dr Roxana Sirli, MD, PhD

Department of Gastroenterology and Hepatology

"Victor Babeș" University of Medicine and

Pharmacy Timişoara, Romania

Phone: $+40-748331233$

E-mail: roxanasirli@gmail.com sensus on when and how it should be inserted into the curricula [1].

Since US is a safe method and provides real-time visualization of moving organs, it seems logical to think that it could be an effective method to facilitate learning anatomy. Indeed, several studies have proved that US is as effective as cadaver dissections or endoscopy [2-4]. Furthermore, students who underwent US training had better physical examination skills [5] and better objective structured clinical examination (OSCE) scores [6].

An important question is when to introduce US for students. As shown before, it is useful for learning anatomy. But what about its utility for clinical skills. A study published more than a decade ago showed that students' exposure to US after traditional practical training, significantly improved their skills, but that it was much less effective if they had not acquired a minimum level of competence in physical examination [7].

In self-assessment questionnaires regarding the usefulness of US in their training, students stated that they were more confident in their ability to perform clinical examination with tangible benefit to their professional education [5,8]. It was also our experience. In 2011, we organized the first workshop - ABC in Ultrasonography, at the students' request. From 2012, Clinical abdominal US was introduced as an optional course in the curriculum of our University. Last year we had an overwhelming attendance, so that we had to organize supplementary courses in order to be able to accommodate all the students who wanted to participate.

A question raised is if US implementation will not impair critical thinking and tactile skills of students, since it relies too much on technology. However, US was never meant to replace clinical examination; it is intended to enhance the traditional way of teaching and learning.

In a very recent systematic review, the question of US training in students was addressed [9]. The conclusion 
of this review was that there is a mild trend to a positive influence of US on physical examination skills of medical students, even if US is not mandatory for achieving proficiency in this domain.

We think that the real utility of US for students would be point-of-care US, or better said as clinical US, used to confirm or refuse a focused question based on assumptions made starting from traditional anamnesis and physical examination. Taught and used this way, US will promote critical and clinical thinking because its application is based on the classical clinical skills of the student, the future physician.

The challenges of integration of US into medical school are linked to costs, teachers' availability, and the time required. However, it was demonstrated that a curriculum could be improved with minimal resources $[6,10]$.

Of course, education in US should continue throughout fellowship training in the respective specialties. When to stop training in US? We are sure that all our readers agree that education in US should never stop, as in all medical domains. Continuous medical education in US should be a reality as well as in any medical specialty.

Thus, as a conclusion to this editorial, education in US should start early and never end!

\section{References}

1. Patel SG, Benninger B, Mirjalili SA. Integrating ultrasound into modern medical curricula. Clin Anat. 2017;30(4):45260 .
2. So S, Patel RM, Orebaugh SL. Ultrasound imaging in medical student education: Impact on learning anatomy and physical diagnosis. Anat Sci Educ. 2017;10(2):176-89.

3. McLachlan JC. New path for teaching anatomy: living anatomy and medical imaging vs. dissection. Anat Rec B New Anat. 2004;281(1):4-5.

4. Knobe M, Carow JB, Ruesseler M, Leu BM, Simon M, Beckers SK, et al. Arthroscopy or ultrasound in undergraduate anatomy education: a randomized cross-over controlled trial. BMC Med Educ. 2012;12:85.

5. Fodor D, Badea R, Poanta L, Dumitrascu DL, Buzoianu $\mathrm{AD}$, Mircea PA. The use of ultrasonography in learning clinical examination - a pilot study involving third year medical students. Med Ultrason. 2012;14(3):177-81.

6. Dinh VA, Frederick J, Bartos R, Shankel TM, Werner L. Effects of ultrasound implementation on physical examination learning and teaching during the first year of medical education. J Ultrasound Med. 2015;34(1):43-50.

7. Butter J, Grant TH, Egan M, Kaye M, Wayne DB, Carrion-Carire V, et al. Does ultrasound training boost Year 1 medical student competence and confidence when learning abdominal examination? Med Educ. 2007;41(9):843-8.

8. Hoppmann RA, Rao VV, Bell F, Poston MB, Howe DB, Riffle $\mathrm{S}$, et al. The evolution of an integrated ultrasound curriculum (iUSC) for medical students: 9-year experience. Crit Ultrasound J. 2015;7(1):18.

9. Oteri V, Occhipinti F, Gribaudo G, Marastoni F, Chisari E. Integration of ultrasound in medical school: effects on physical examination skills of undergraduates. Medical Science Educator. 2020; 30:417-427

10. Mullen A, Kim B, Puglisi J,Mason NL. An economical strategy for early medical education in ultrasound. BMC Med Educ. 2018;18 (1):169. 